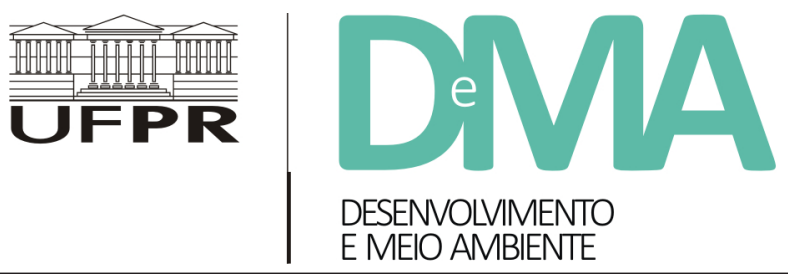

\title{
Planejamento participativo para a gestão da orla marítima de Galinhos/RN, nordeste brasileiro, com apoio de sensores remotos e modelagem costeira
}

\section{Participative Planning for Managing the Seashore of Galinhos, Rio Grande do Norte, Northeast Brazil, Using Remote Sensing Support and Coastal Modeling}

\author{
Ana Maria Teixeira MARCELINO ${ }^{1 *}$, Lívian Rafaely de Santana Gomes PINHEIRO ${ }^{1}$, Juliana Rayssa Silva \\ COSTA $^{1}$ \\ ${ }^{1}$ Instituto de Desenvolvimento Sustentável e Meio Ambiente do Rio Grande do Norte (IDEMA), Natal, RN, Brasil. \\ *E-mail de contato: anamarcelino.idema@gmail.com
}

Artigo recebido em 1 de setembro de 2017, versão final aceita em 3 de dezembro de 2017.

RESUMO: Este trabalho objetivou trazer à discussão a experiência de planejamento e gestão costeira da orla marítima do município de Galinhos no Litoral Setentrional do Rio Grande do Norte, a partir da aplicação da metodologia proposta para a elaboração do Plano de Gestão Integrada da Orla Marítima (PGI), utilizando-se como ferramentas complementares ao planejamento estratégico e participativo o uso do Sistema de Modelagem Costeira do Brasil (SMC-Brasil), do sensoriamento remoto e do levantamento complementar por Veículo Aéreo Não Tripulado (VANT). Tais ferramentas, aliadas à metodologia de oficinas participativas proposta pelo Projeto Orla, permitiram agregar conhecimento técnico ao tradicional local. Tais metodologias contribuíram para a identificação das modificações da linha de costa e a espacialização da expansão do uso do espaço territorial restrito e sujeito aos processos naturais da dinâmica costeira. A modelagem apontou para a intensa energia de ondas sobre a península, fluxo médio anual de $366,43 \mathrm{~J} / \mathrm{m} . \mathrm{s}$, com transporte longitudinal de $185.839 \mathrm{~m} 3 /$ ano de sedimentos da praia, com tendência de abertura de canal isolando o pontal arenoso. $\mathrm{O}$ cálculo da planta de equilíbrio das enseadas de Galinhos e Galos indica tendência de avanço da linha de costa em aproximadamente $80 \mathrm{~m}$ e $120 \mathrm{~m}$ em direção a estes distritos, respectivamente. A revisão do PGI serviu também como registro de informações que serão aportadas como subsídio à elaboração do Plano Diretor Participativo (PDP) do município. Concluiu-se que tais ferramentas e tecnologias são imprescindíveis no processo de planejamento para a gestão integrada da orla marítima. Permitem ampliar a compreensão sobre a dinâmica costeira junto aos moradores das praias, gestores locais e demais atores-chaves para a efetivação do PGI e do PDP, dentre outros instrumentos de gestão territorial e ambiental em áreas próximas à linha de costa. 
Palavras-chave: erosão costeira; planejamento territorial; Projeto Orla; modelagem costeira; sensoriamento remoto.

ABSTRACT: This work aims to raise the discussion about the experience of coastal planning and management for the seashore of Galinhos municipality, a town located in the Northern coast of the State of Rio Grande do Norte, by applying the methodology proposed for the Seashore Integrated Management (SIM), and complementary tools for strategic and participative planning, such as the Brazilian Coastal Modeling System (SMC - Brazil), remote sensing and image survey by unmanned aerial vehicle. These tools associated with participative workshops as proposed by the Seashore Project made possible to locate coastal line modifications and the spatial expansion of land uses in strictly use-controlled territorial areas which are subject to natural geodynamic processes. The modeling indicated an intense wave of energy reaching the peninsula, with an annual average flow of $366,43 \mathrm{~J} / \mathrm{m} . \mathrm{s}$, and with the transportation of $185.839 \mathrm{~m} 3 /$ per year of beach sediments, with a tendency of opening a canal and isolating the sandspit. Estimation of the plan-shape equilibrium of Galinhos and Galos districts bays indicates a trend of shoreline transgression of around $80 \mathrm{~m}$ and $120 \mathrm{~m}$ in their direction, respectively. The SIM review also served to collect data that will be useful for devising the Participative Land Use Master Plan of the Municipality (PDP, in Portuguese). Such tools and technologies are indispensable, therefore, in the process towards an integrated management planning of the coast. They allow for a better understanding of the coastal dynamics by locals, by local managers and by other key actors in charge of undertaking the SIM and PDP, among other instruments of territorial and environmental management of areas located near the coastline.

Keywords: coastal erosion; land planning; Orla Project; coastal modeling; remote sensing.

\section{Introdução}

A zona costeira é a área de urbanização mais antiga do Brasil. Segundo Loureiro-Filho (2014), dos dezoito primeiros núcleos fundados pelos portugueses, apenas São Paulo não se encontrava à beira-mar. Observa também o autor que o processo de ocupação da zona costeira brasileira é composto por uma sucessão de ciclos. Iniciou-se com a colonização da borda litorânea, ainda no século XVI, seguida de uma grande tendência ao aumento da concentração demográfica devido à crescente ocupação da zona costeira, sem a preocupação com áreas de fragilidade ambiental, como os estuários, os manguezais, as dunas, as penínsulas, dentre outros.

Diante do contexto histórico de ocupação e dos consequentes problemas na zona costeira, em 1988 foi instituído o Plano Nacional de Gerenciamento
Costeiro (PNGC) pela Lei 7.661. O Rio Grande do Norte $(\mathrm{RN})$ realiza atividades relacionadas à gestão costeira desde 1983, quando fez parte da realização de pesquisas aplicadas que contribuíram para a definição da Política de Gerenciamento Costeiro no Brasil. A Política Estadual de Gerenciamento Costeiro foi concretizada pela Lei 6.950/1996, que instituiu o Plano Estadual de Gerenciamento Costeiro (PEGC).

Durante o processo de evolução desta ação pública, alguns instrumentos foram introduzidos nas atualizações do PNGC, culminando com a publicação do Decreto 5.300/2004, que regulamentou a Lei de Gerenciamento Costeiro. O decreto trouxe, entre outras normatizações, orientação para a implementação do Projeto Orla, tendo como instrumento o Plano de Gestão Integrada da Orla Marítima (PGI). Esta ação buscou desenvolver um procedimento de 
planejamento e gestão específico para esta faixa do território. A gestão integrada da zona costeira visa ao desenvolvimento econômico pautado no uso equilibrado dos recursos ambientais, considerando a necessidade da proteção, em virtude da fragilidade ambiental reconhecida, inclusive, pela Carta Magna de 1988.

Uma área particularmente sensível no RN é a orla do município de Galinhos, Litoral Setentrional do Estado, universo de estudo deste trabalho, onde estão instalados o seu núcleo urbano e o distrito de Galos, os dois maiores aglomerados populacionais do município, com aproximadamente 2.159 habitantes (IBGE, 2010). A expansão dos núcleos habitacionais sobre dunas e praias gera conflitos socioambientais e de uso e ocupação do solo, provocados pelo avanço do mar e das dunas em direção às residências. Tais ocorrências exigem do poder público a busca de soluções em conjunto com a população local, de maneira a viabilizar a gestão municipal.

Um dos aspectos que dificulta ainda mais a gestão deste frágil espaço costeiro é a ausência de instrumentos municipais que orientem o uso e a ocupação do solo e a utilização sustentável dos recursos naturais. O único instrumento de ordenamento territorial existente até o momento é a primeira versão do
PGI, construído participativamente, como orienta a metodologia do Orla, elaborado após a adesão do município ao Projeto.

O Comitê Gestor da Orla Marítima foi instituído pelo Decreto Municipal no 002, de 08.01.2009, com caráter deliberativo, formado por 24 membros, com representação paritária entre instituições públicas e sociedade civil organizada ${ }^{1}$. A não existência do PDP e de outros instrumentos legais que deem respaldo à implantação do PGI, associada à carência de corpo técnico capacitado da Prefeitura para a gestão ambiental e territorial, acentua mais ainda as dificuldades na manutenção do equilíbrio ambiental dessa área extremamente frágil.

Estudo realizado pelo Ministério do Meio Ambiente (MMA), desenvolvido no período de 2002 a 2005, no âmbito do Programa Nacional da Diversidade Biológica (PRONABIO), por meio do Projeto Conservação e Utilização da Diversidade Biológica Brasileira (PROBIO) ${ }^{2}$, mapeou as áreas prioritárias para a conservação, a utilização sustentável e a repartição dos benefícios da biodiversidade no Brasil. Dentre estas áreas está o Complexo Estuarino de Galinhos e Guamaré, no RN, com prioridade muito alta para conservação, propício ao manejo, recuperação ambiental e criação de Unidade de Conservação para a proteção da Zona Costeira.

\footnotetext{
${ }^{1} \mathrm{O}$ comitê é composto por 12 instituições governamentais: Secretaria do Patrimônio da União (SPU), Instituto de Desenvolvimento Sustentável e Meio Ambiente do Rio Grande do Norte (IDEMA), Instituto Brasileiro de Meio Ambiente e dos Recursos Naturais Renováveis (IBAMA), Universidade Federal do Rio Grande do Norte (UFRN), Instituto Federal de Educação, Ciência e Tecnologia do Rio Grande do Norte (IFRN), Câmara Municipal, Sec. de Turismo, Sec. de Meio Ambiente, Sec. de Obras, Sec. de Saúde, Sec. de Educação, Sec. de Assistência Social; e por 12 entes não governamentais: Petróleo Brasileiro S.A. (PETROBRAS), Salina Diamante Branco, Associação de Pescadores, Associação de Bugueiros, Associação de Barqueiros, Associação de Charreteiros, Associação das Artesãs de Galinhos, Associação de Pousadeiros de Galinhos, Grupo de Jovens, Grupo de Idosos, Bares e Restaurantes, Esporte Naútico.

${ }^{2}$ O PROBIO contemplou as Zonas Costeira e Marinha e os biomas Amazônia Brasileira, Caatinga, Cerrado e Pantanal, Mata Atlântica e Campos Sulinos (MMA, 2003). Esta ação governamental buscou, dentre outros objetivos, integrar o Programa de Gerenciamento Costeiro (GERCO) com o PRONABIO, fortalecer o ordenamento da orla marítima (Projeto Orla) e implementar a gestão ambiental urbana (drenagem, saneamento básico).
} 
Galinhos detém em seu território a produção de sal marinho, de camarão em cativeiro, a atividade pesqueira, o turismo e, mais recentemente, parques eólicos sobre os campos de dunas. Os passeios turísticos nas dunas e no estuário representam a principal fonte de renda para a população local, além do funcionalismo público e do pequeno comércio. Todas essas atividades têm estreita relação com a orla marítima, o que motivou a revisão do PGI, associada ao desenvolvimento de estudos com a utilização de tecnologias como o SMC-Brasil e o sensoriamento remoto, entre outras ferramentas para auxiliar no ordenamento territorial do município.

O objetivo primordial deste trabalho é, portanto, contribuir com dados técnico-científicos para a ampliação do conhecimento da população e dos gestores sobre a dinâmica costeira e a erosão, bem como gerar dados que possam servir de subsídio ao PGI e aos demais instrumentos de planejamento e gestão territorial e ambiental.

\section{2. Área de estudo}

O Município de Galinhos está inserido na porção do Litoral norte-rio-grandense, denominado Litoral Setentrional (Figura 1) para efeito das ações do PEGC.

O município consiste em um espaço territorial recortado por região de caatinga no tabuleiro cos-

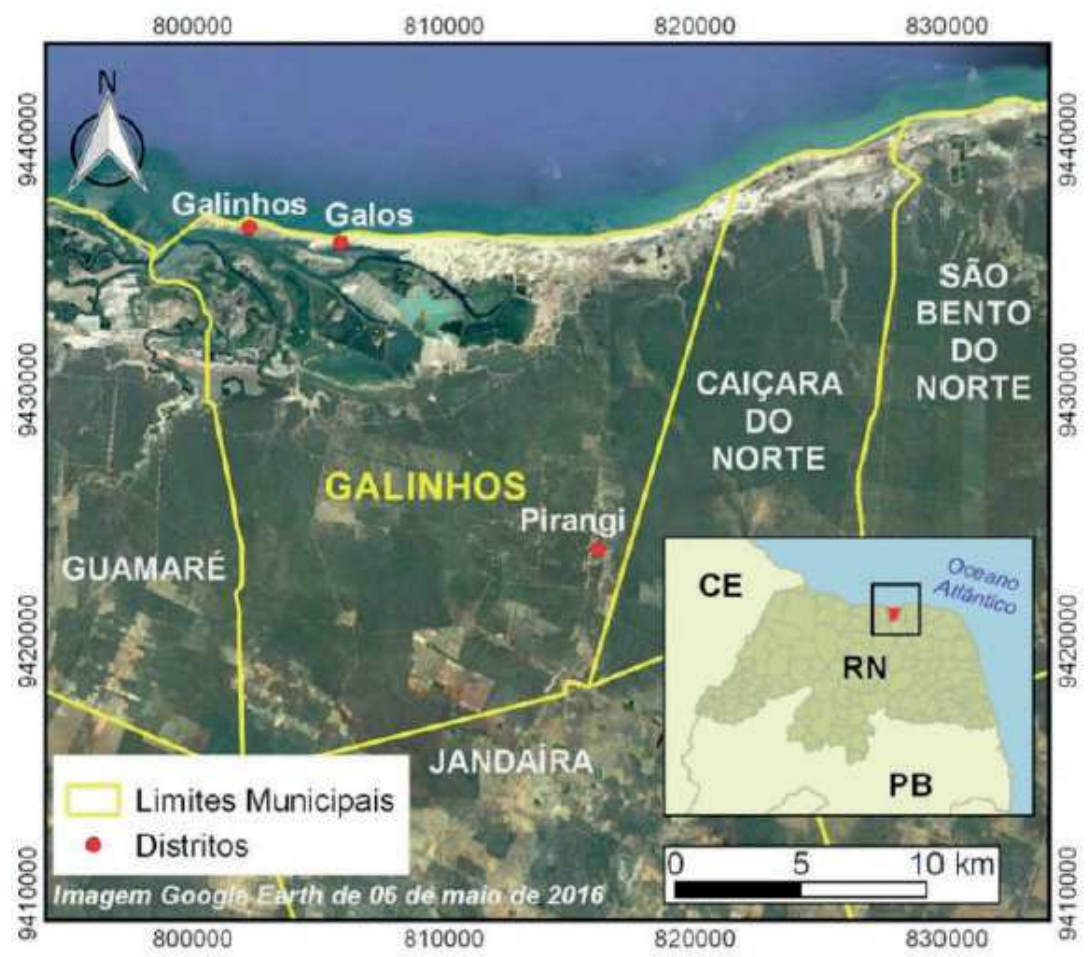

FIGURA 1 - Localização do Município de Galinhos/RN. 
teiro, ampla região estuarina, campos de dunas e uma península com área litorânea particularmente sensível. A sede municipal Galinhos é o mais importante núcleo populacional, seguido do distrito de Galos, ambos instalados na península, em ambiente restrito e não favorável à expansão, conforme será explanado no decorrer deste trabalho. O terceiro núcleo habitacional é a sede do assentamento rural Pirangi, situado na região do tabuleiro. Os nomes Galinhos e Galos fazem referência aos peixes-galo encontrados na região, os grandes nas proximidades do lugar hoje denominado Galos, e os menores na região de Galinhos.

Esses núcleos populacionais, segundo dados do IBGE de 2010, somavam 2.159 habitantes, representando uma densidade demográfica de 6,31 $\mathrm{hab} / \mathrm{km}^{2}$. A população estimada para 2017, segundo o Instituto, é de 2.715 habitantes.

Por um lado, a paisagem exuberante funciona como excelente atrativo e leva para Galinhos intensas atividades de recreação, lazer e turismo. Por outro lado, a expansão da atividade turística tem contribuído para acelerar a ocupação irregular dos núcleos populacionais e seus entornos, situados na península, com construções em áreas públicas e de preservação permanente (APP).

Essa ocupação crescente tem gerado resíduos sólidos e efluentes residenciais, de pousadas, de escolas e do comércio. Pela ausência de sistema de coleta e tratamento de esgoto, utilizam-se fossas sépticas com infiltração no solo. O lixo coletado é depositado em depressões do campo dunar próximas a Galinhos e a Galos, motivo de grande preocupação da população e da administração local. A água para uso comum é captada em poços rasos, geralmente com teor de salinidade e risco de poluição do lençol freático por efluentes das fossas sépticas. Em decor- rência disto, a população consome água mineral vinda do continente ou a água de dessalinizadores que estão sendo instalados por medida de compensação ambiental de parque eólico implantado na região.

Os resultados dos estudos desenvolvidos pelo GERCO-RN, coordenado pelo Instituto de Desenvolvimento Sustentável e Meio Ambiente (IDEMA), para a elaboração do Zoneamento Ecológico-Econômico Costeiro (ZEEC) do Litoral Setentrional, em 2004, confirmaram a indicação do PROBIO (2002/2005), que a região estuarina de Galinhos, Guamaré e adjacências tem potencial para conservação ambiental (Figura 2).

O Litoral Setentrional recebe o efeito dos ventos alísios de sudeste e de nordeste, à medida em que a Zona de Convergência Intertropical (ZCIT) migra longitudinalmente ao longo do ano. Este é o principal sistema atmosférico de ampla escala que condiciona a precipitação nessa parte do $\mathrm{RN}$, que pode ser intensificada pela penetração de sistemas frontais até latitudes equatoriais (Melo et al., 2009).

De acordo com dados da estação meteorológica de Macau, mantida pelo Instituto Nacional de Meteorologia (INMET), Galinhos está em região de clima semiárido quente de baixas latitudes e altitudes, do tipo Bsh pela classificação de Köppen (Álvares et al., 2014), com período chuvoso concentrado entre os meses de fevereiro e maio pela Normal Climatológica medida entre 1961 e 1990, média anual de 507,2 $\mathrm{mm}$ precipitados. Os ventos vêm predominantemente de sudeste, com velocidades de 4,29 a $6,92 \mathrm{~m} / \mathrm{s}$, com ventos mais intensos entre os meses de agosto e dezembro.

Segundo dados da Estação Maregráfica do Porto de Guamaré, da Diretoria de Hidrografia e Navegação da Marinha do Brasil (DHN), a alternância entre preamar e baixa-mar é de aproximada- 
mente seis horas, com amplitude média de 2,25 m em sizígia. O nível médio é 1,34 $\mathrm{m}$ acima do nível de redução (NR), podendo ser classificado como regime de mesomaré semidiurna pela classificação de Davis (1964). A circulação da Corrente Norte do Brasil condiciona a direção predominante da deriva litorânea de leste para oeste (Peterson \& Stramma, 1991).
A área de estudo é inserida no substrato da Bacia Potiguar, de idade cretácea, superposto por depósitos quaternários costeiros que conformam a paisagem (Pessoa-Neto et al., 2007). A linha de costa de Galinhos pode ser dividida em dois segmentos pela sua forma em planta, a saber: (i) na região mais oriental, é próxima de retilínea com direção leste-oeste; (ii) a porção mais ocidental, com
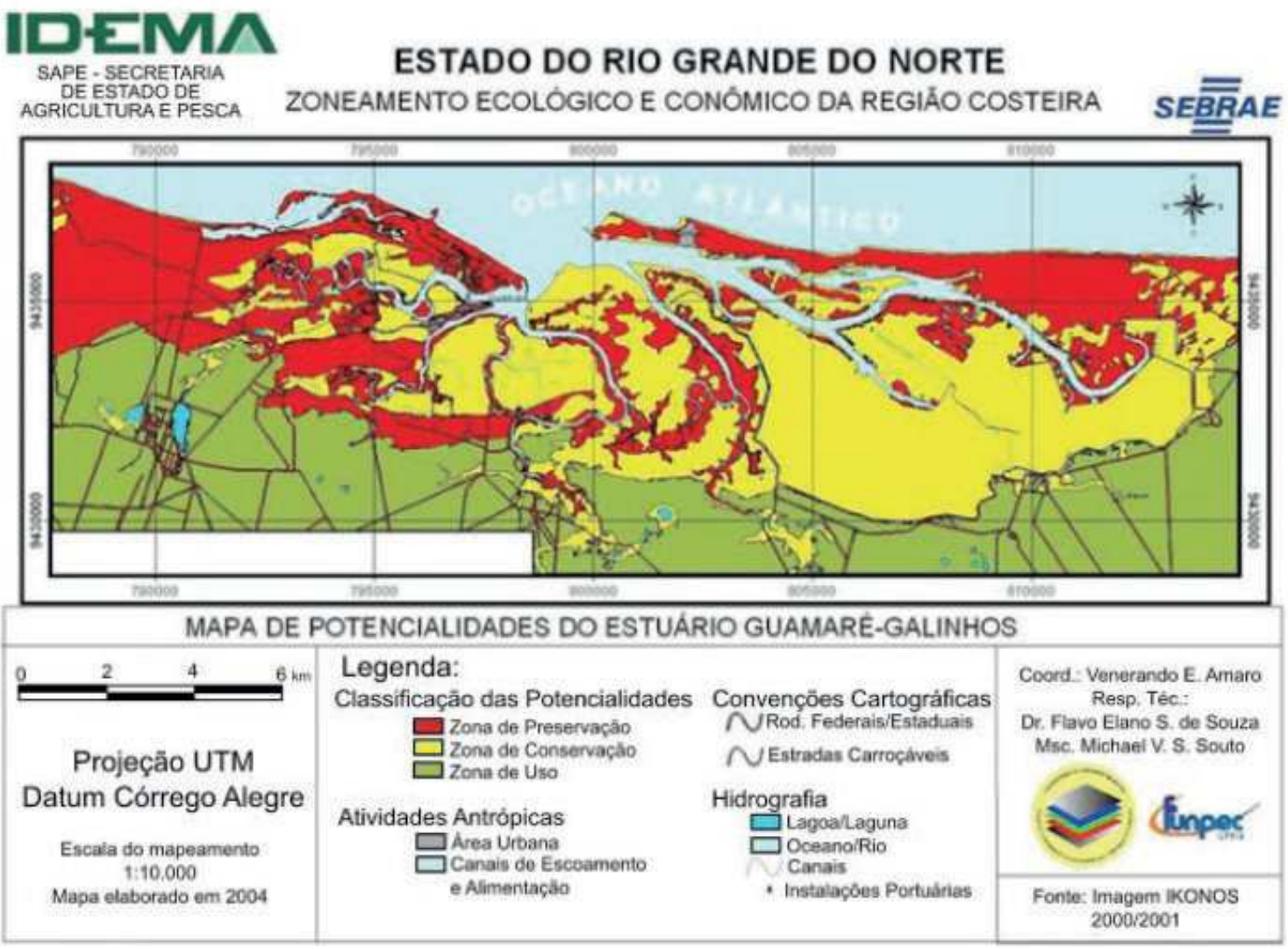

FIGURA 2 - Mapa de potencialidades do Estuário Guamaré-Galinhos.

FONTE: IDEMA (2004). 
duas reentrâncias em baía, em frente aos núcleos populacionais de Galinhos e Galos, culminando na península arenosa ladeada ao norte pelo Oceano Atlântico e pelo estuário ao sul (Figura 1).

\section{Metodologia}

Para este estudo, optou-se por adotar o conceito de Unidade de Paisagem constante nos Fundamentos para Gestão Integrada da Orla (MMA, 2002b), que atende às diferentes escalas de abordagem como sendo

(...) trecho que apresenta uma homogeneidade de configuração, caracterizada pela disposição e dimensão similares dos quatro elementos definidores da paisagem: suporte físico, estrutura/ padrão de drenagem, cobertura vegetal e mancha urbana. Para efeito de estudo, qualquer uma das grandes unidades de paisagem litorânea pode ser subdividida em subunidades, de modo a permitir um aprofundamento do conhecimento. (MMA, 2002b, p. 38).

Tomando como ponto de partida estudos pretéritos como os desenvolvidos pelo $\mathrm{PROBIO/}$ MMA e o mapeamento das potencialidades para a região estuarina de Galinhos e Guamaré para o ZEEC desenvolvido pelo IDEMA (Figura 2), estruturou-se o presente trabalho com base no seguinte procedimento: (i) Coleta de material bibliográfico e cartográfico para caracterização prévia da área de estudo; (ii) oficina participativa utilizando metodologia do Projeto Orla, com a delimitação das Unidades de Paisagem com a utilização de produtos de sensores remotos; e (iii) Modelagem Costeira por meio do SMC-Brasil, os quais serão descritos em itens à frente.

\subsection{Material bibliográfico e cartográfico}

Foram realizados: levantamento, catalogação, leitura de documentos e resultados de pesquisas, além da obtenção de dados espacializados sobre o meio físico e socioeconômico do município de Galinhos.

Foram utilizadas imagens históricas do Timelapse Google Earth Engine ${ }^{\odot}$ (1984-2016). A plataforma on-line é gratuita para fins de pesquisa e educação e apresenta a evolução do terreno em animação das imagens de satélites de várias missões, pré-processadas e georreferenciadas pela equipe responsável (Gorelick et al., 2017). Estes foram complementados com o imageamento da área da península e do estuário com apoio de VANT do fabricante DJI, modelo Phantom3 Professional, câmera com capacidade de 12 megapixels no espectro do visível, sobrevoo em altitude de $100 \mathrm{~m}$, com sobreposição lateral de $65 \%$ e frontal de $75 \%$.

\subsection{Oficinas participativas}

Em agosto de 2016, realizou-se oficina de trabalho com o objetivo de revisar o primeiro PGI de Galinhos, contando com a participação do Comitê e de outras pessoas da comunidade.

Conforme a metodologia utilizada para a elaboração ou a revisão do PGI, a oficina foi desenvolvida em três momentos distintos: (i) Abertura dos trabalhos pelo gestor do município; (ii) apresentação da versão existente do PGI pela Coordenadora do Comitê; (iii) apresentação pela equipe técnica do IDEMA, de recorte de imagem de satélite para discussão e delimitação das Unidades de Paisagem; (iv) a partir destas informações iniciais, foram defi- 
nidos os trechos a serem analisados em campo e a divisão de grupos de trabalho para discussão e avaliação dos conflitos identificados pelos participantes nos seguintes locais: orla marítima oceânica, orla marítima adjacente ao canal estuarino, manguezal no trecho das fazendas de camarão e no trecho ocupado pela salina; (v) sistematização da identificação dos conflitos observados e apontamento das possíveis soluções, responsabilidades e prazos para a execução das ações de gestão.

Os apontamentos estão sendo elencados e sintetizados em tabelas adaptadas do Manual de Gestão da metodologia do Projeto Orla (MMA, 2002a) (Figura 3).

Para a elaboração do mapa de Unidade de Paisagem, utilizou-se recorte de imagem de satélite

\begin{tabular}{|l|l|l|l|l|l|}
\hline $\begin{array}{l}\text { Conflitos } \\
\text { existentes }\end{array}$ & Trechos & $\begin{array}{c}\text { Atividades Geradoras } \\
\text { do Conflito }\end{array}$ & $\begin{array}{c}\text { Atores Sociais } \\
\text { envolvidos }\end{array}$ & $\begin{array}{c}\text { Atores } \\
\text { Institucionais }\end{array}$ & Legislação \\
\hline & & & & & \\
\hline
\end{tabular}

\begin{tabular}{l}
\hline \multicolumn{3}{|l|}{ Trecho(s): } \\
\begin{tabular}{|c|c|c|}
\hline Conflito: \\
\hline Problemas & Efeitos e Impactos & Linhas de Ação \\
\hline & & \\
\hline
\end{tabular}
\end{tabular}

FIGURA 3 - Tabelas utilizadas para a caracterização dos conflitos na orla (acima) a para os conflitos por trechos (abaixo). FONTE: Adaptado do Manual de Gestão do Projeto Orla (MMA, 2002a).

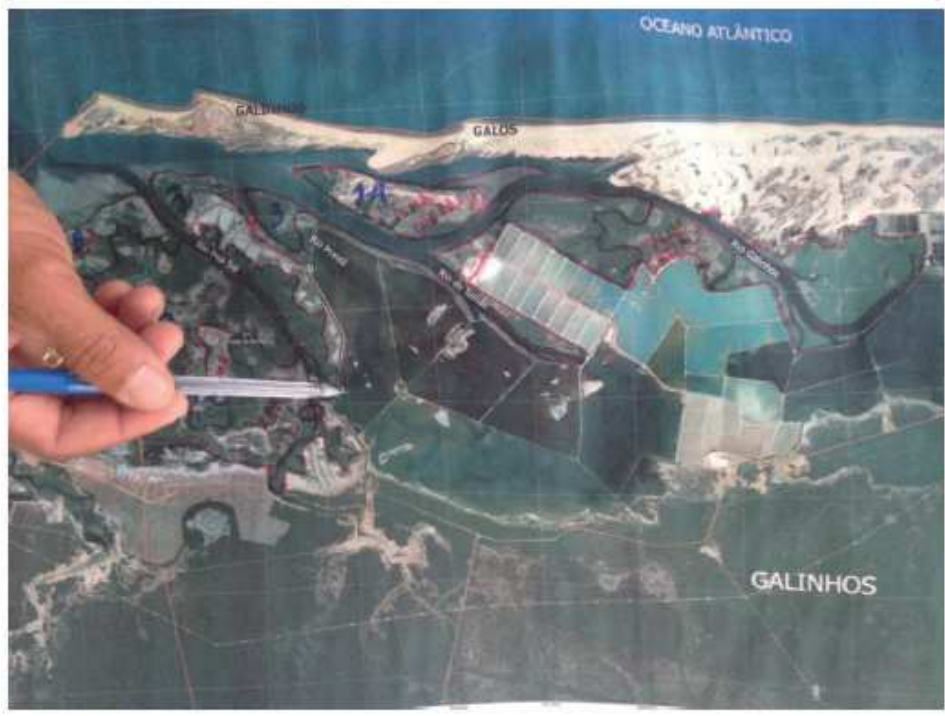

FIGURA 4 - Delimitação das Unidades de Paisagem de Galinhos pelos participantes da oficina elaborado a partir de imagens de satélite. FONTE: Google Earth@, de 05.05.2016. 
do Google Earth ${ }^{\odot}$ de 05 de maio de 2016, apresentado na Figura 4, impresso em folhas A0, em escala compatível à leitura dos participantes da oficina. Este procedimento contribuiu para que a população pudesse debater com base em informações técnicas sobre o meio ambiente de Galinhos, abordando-se, dentre outros aspectos, a expansão da ocupação relacionada à erosão costeira. Esta etapa auxiliou os participantes da oficina na delimitação das Unidades de Paisagem e dos trechos a serem observados em campo pelos grupos de trabalho.

\subsection{Modelagem costeira}

O SMC-Brasil (IH-Cantábria, 2013) foi aplicado para avaliar especialmente os processos costeiros e estimar quantitativamente as variações na linha de costa nas praias marítimas de Galinhos ${ }^{3}$. O SMC-Brasil foi transferido por meio de um Acordo de Cooperação Técnica e Científica firmado ao ano de 2010 entre a Agência Espanhola de Cooperação Internacional para o Desenvolvimento (AECID), o Ministério do Meio Ambiente do Brasil (MMA) e o Ministério do Planejamento, Orçamento e Gestão, Secretaria do Patrimônio da União (MPOG-SPU). Diversos grupos de pesquisa e órgãos da gestão pública estão aplicando o SMC-Brasil em estudos de caso e/ou demandas de planejamento dos espaços costeiros (e.g., Oliveira, 2013; Almeida et al., 2015; Araújo et al., 2015; Ribeiro et al., 2015; Silva et al., 2016).
O clima de ondas foi gerado pelo Downscaling Ocean Waves (DOW), banco de dados de reanálise com série temporal de resolução horária do SMC-Brasil, entre os anos de 1948 e 2008, baseado nos modelos Wavewatch-III e SWAN (Camus et al., 2013). O DOW forneceu dados de parâmetros espectrais em termos de sua probabilidade de ocorrência no ponto (IH-CANTABRIA, 2012), a saber: altura significativa de onda (Hs), período médio (Tm), período de pico (Tp) e direção média de onda $(\theta \mathrm{m})$, em termos de regime médio (índice $\left.{ }_{50}\right)$ e extremo (índice ${ }_{12}$ ) das condições de mar. Além disso, cada ponto DOW fornece curva de maré astronômica e meteorológica projetada desde os marégrafos da Diretoria de Hidrografia e Navegação da Marinha do Brasil até o local de interesse.

Os pontos DOW foram coletados entre 20 e 5 metros de profundidade (Figura 5), para se identificar a variabilidade dos resultados do SWAN pela interferência do leito de fundo, encontrando pontos representativos para ambos os conjuntos de malhas de simulação. Como a análise estatística do SMC-Brasil é interna e apenas gráficos e tabelas de probabilidade de ondas são disponibilizados ao usuário, a comparação entre eles ocorreu por Regressão Linear Simples dos estados de mar. Testes estatísticos de distribuição normal e aleatória dos erros residuais não puderam ser realizados. O ponto P05 foi selecionado como referência, tendo em vista que o SWAN ainda tem boa resposta até essa profundidade, na plataforma setentrional do RN (Matos et al., 2013).

\footnotetext{
${ }^{3}$ A modelagem com SMC-Brasil não contempla a porção abrigada do estuário, por limitações das suas equações. A integração do SMC-Brasil com outro sistema de modelagem que permita o entendimento do processo completo, incluindo as porções marinha e estuarina da península, poderá ser um desdobramento deste trabalho.
} 
Pela extensão da linha de costa de Galinhos e de sua plataforma continental, foi necessário dividir a simulação em duas etapas, cada uma relacionada a um segmento da orla, de maneira a otimizar o tempo de processamento e a qualidade dos resultados.

Os domínios computacionais foram definidos nas malhas de simulação (Figura 5), configuradas para comportar ao menos $90 \%$ do espectro direcional de ondas que chegam ao seu contorno mais externo. Por recomendação do próprio IH-Cantábria, ao menos $15 \%$ das bordas da malha tiveram seus resultados desconsiderados, em função de problemas de contorno que advêm dos algoritmos de propagação. Para sanar essa situação, os limites das malhas ultrapassaram os limites do município de Galinhos e dos trechos da modelagem.
A batimetria final foi oriunda da integração entre a Base de Batimetrias e Cartas Náuticas da Costa (IH-DATA BACO) do SMC-Brasil e as cartas náuticas 720 e 704 da Marinha do Brasil, digitalizadas por captura de tela. Nesta modelagem, o nível zero da modelagem se refere ao nível de redução da carta naútica 704 - que é de 1,4 m abaixo do nível médio local.

Os estados de mar com maiores probabilidades de ocorrência - baseando-se nos dados DOW - foram propagados até a linha de costa, em situação de marés alta e baixa, em condições médias e de tempestade. Essa é uma análise em curto prazo, tratando da gama de ondulações que incide sobre a praia e das correntes longitudinais que propiciam o transporte de sedimentos, relacionadas a uma

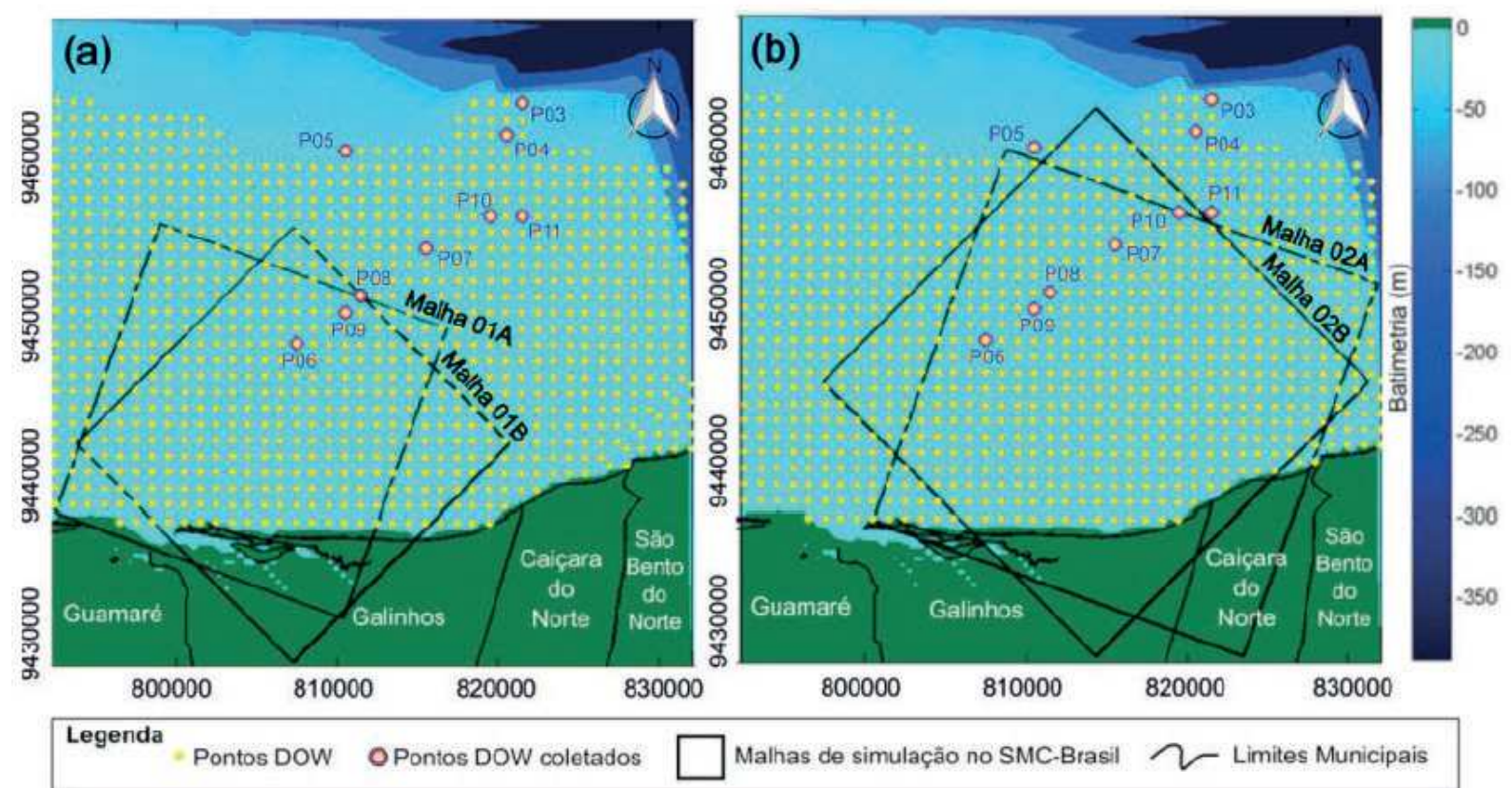

FIGURA 5 - Plano de trabalho da modelagem no SMC-Brasil. Em destaque, Pontos DOW coletados no SMC-Brasil, para análise do clima de ondas na plataforma adjacente à Galinhos. Malhas de simulação da orla marítima de Galinhos com SMC-Brasil, utilizadas na modelagem (a) do trecho oeste e (b) do trecho leste. 
agitação marítima imediata. Essa propagação foi realizada pelo Modelo de Propagação de Ondas Espectral OLUCA-SP, que discretiza uma função de densidade de probabilidade em um número de seções de energia, às quais são associados componentes da onda.

Como material de apoio à parametrização da modelagem, recorreu-se aos levantamentos sedimentares de Lima et al. (2003) e Vital et al. (2008).

A linha de arenitos foi digitalizada a partir da imagem Google Earth ${ }^{(\mathrm{c})}$ de 05 de junho de 2016, para identificar o efeito destas feições na hidrodinâmica das praias de Galinhos. Também foram empregadas fotografias aéreas oblíquas do IDEMA, datadas de 2006 e 2009, além das imagens oblíquas e mosaico obtidos pelo VANT.

Em longo prazo, calculou-se o fluxo médio anual vetorial de energia $F_{m}$ (Equação 1 ), a intensidade, dada pela Equação 2, e o transporte potencial de sedimentos em 16 perfis na plataforma rasa, ao longo de toda a costa marítima do município de Galinhos, com base nos 60 anos de dados da série DOW, pela equação do Coastal Engineering Research Center (CERC), incorporada pelo SMC-Brasil segundo a Equação 3 (IH-Cantábria, 2014).

$$
\underset{F_{m}}{\mathbb{W}}=\frac{1}{8760}\left(\sum_{t=1 h}^{8760} F_{x, t} \vec{i}+\sum_{t=1 h}^{8760} F_{y, t} \vec{j}\right)
$$

onde: $h$ é a contagem do tempo $t$ em horas, $x$ e $y$ são as direções em campo vetorial, com $i$ e $j$ seus respectivos vetores unitários.

$$
F=\frac{1}{8} \rho g H^{2} C_{g}
$$

(Equação 2) onde: $H$ é a altura do grupo de ondas, $C_{g}$ corresponde à velocidade do grupo, $\rho$ à densidade da água, e $g$ é a aceleração da gravidade.

$$
Q=\frac{K \rho g^{\frac{1}{2}}}{16\left(\rho_{s}-\rho\right)(1-\rho) \sqrt{\gamma_{b}}} H_{b}^{\frac{s}{2}} \operatorname{sen}\left(2 \theta_{b}\right)
$$

(Equação 3)

onde: $Q$ é a taxa de transporte longitudinal anual, $\rho_{s}$ é a densidade do material transportado, $\rho$ é a densidade da água, $g$ representa a aceleração da gravidade, $K$ um coeficiente adimensional que relaciona o peso imerso do sedimento ao fluxo de energia de onda que entra na zona de surfe, $H_{b}$ a altura de onda na zona de arrebentação, $\gamma_{b}$ o índice de quebra das ondas na zona de arrebentação e $\theta_{b}$ o ângulo entre as frentes de ondas no início da sua quebra e a orientação da linha de costa.

Além disso, foi simulada a resposta morfodinâmica da forma em planta das praias em enseada em frente aos núcleos urbanos de Galinhos e Galos, em termos da tendência decadal de variação da linha de costa. Essa abordagem vem de Hsu \& Evans (1989) e foi adaptada por González \& Medina (2001), sendo capaz de indicar a condição geométrica de equilíbrio em planta da linha de costa associada aos promontórios originados pela conformação dos arenitos de praia na área de estudo. $\mathrm{O}$ modelo é baseado na equação da espiral logarítmica, ao que a enseada e o segmento mais retilíneo da praia estão associados no mesmo sistema dinâmico de deslocamento da linha de costa, condicionado pela difração de ondas em algum ponto adjacente ao promontório.

Não foi viável realizar o cálculo do perfil de praia e cota de inundação, em função da falta de 
dados topobatimétricos devidamente integrados e com resolução espacial suficiente para essa análise.

\section{Resultados e discussão}

Durante a vigência do primeiro PGI, instrumento que considera as questões ambientais e patrimoniais, as discussões e as ações do Comitê Gestor apontaram para a atualização do Plano, em andamento. $\mathrm{O}$ exercício coletivo na busca de soluções para os problemas e conflitos existentes contribuiu para que o Comitê compreendesse um pouco mais a complexidade da área em termos ambientais e sociais. Isto levou à conclusão de que, além da atualização do PGI, seria necessária a elaboração de outros instrumentos que dariam base à implantação do plano da orla, dentre eles, e prioritariamente, a implementação da política ambiental do município com a instituição do Código de Meio Ambiente e o PDP, a serem complementados pelo Código de Posturas e o Código de Obras.

No processo de discussão para a revisão do PGI, a partir da divulgação dos estudos e das informações técnicas geradas pelo IDEMA, órgão am- biental do Estado e integrante do Comitê Gestor da Orla, percebeu-se a ampliação do conhecimento da população local sobre a erosão costeira presente na península. Essa percepção existia, sem, no entanto, ser compreendida em sua extensão e seus desdobramentos. Entrou na pauta de debates da revisão do PGI a constatação da população local sobre o tema, respaldada com base técnica, que demonstrou a redução de terreno pela perda dos sedimentos, provocando o avanço relativo do mar sobre as edificações. Além disto, outros efeitos associados foram identificados, como a salinização do solo e dos recursos hídricos, a exposição do manguezal a maior agitação marítima e o assoreamento do canal adjacente à península.

A Figura 6 registra o exercício para a delimitação das Unidades de Paisagem previamente ao trabalho de campo que permitiu identificar os problemas e os conflitos existentes pelos grupos de trabalho. Observou-se que a iniciativa da administração municipal em retomar o planejamento integrado da Orla Marítima estava sendo apoiada pelos segmentos organizados da população local, motivados pela necessidade de dar continuidade ao
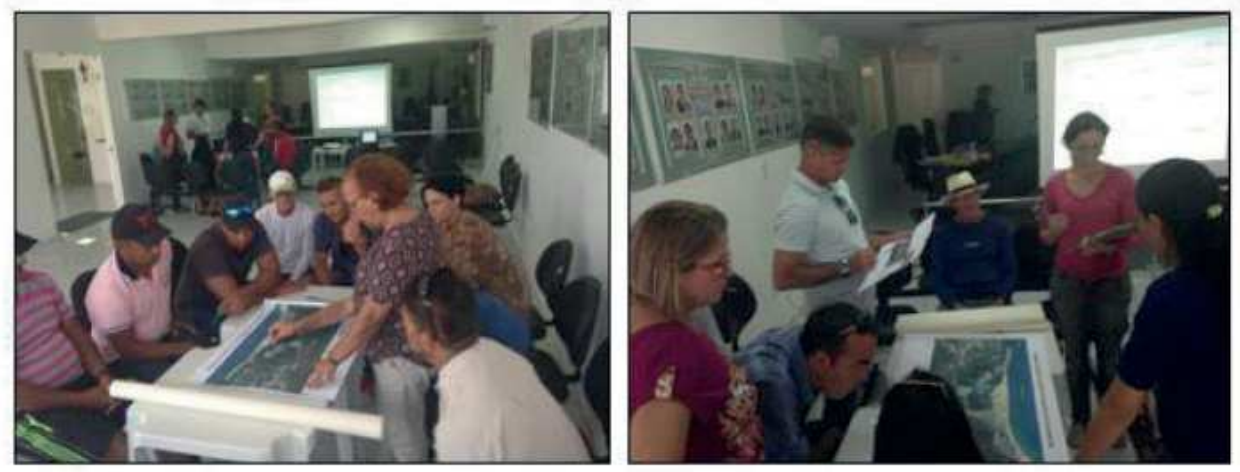

FIGURA 6 - Registro fotográfico da oficina de trabalho realizada em 18.08.2016. 
Projeto Orla, iniciado em 2009 e paralisado na administração anterior. Essa pausa ampliou os problemas e os conflitos identificados durante a elaboração do primeiro PGI. O Comitê Gestor se esforçou na busca de parcerias e de auxílio das instituições para a gestão da orla, trabalho que se perdeu no tempo, pela descontinuidade.

As Unidades de Paisagem da orla de Galinhos, como identificadas nas oficinas e em visita em campo realizada pelos seus participantes, são compostas por ilhas estuarinas, manguezal, dunas móveis e parcialmente vegetadas, dunas frontais, praias arenosas e recifes de arenitos (Figura 7).
Os problemas e os conflitos que mais se destacaram no levantamento dos grupos de trabalho foram: questão fundiária versus necessidade de ampliação do número de moradias em áreas de praia ou próximo a elas; lixão a céu aberto em campo de duna e próximo à linha de costa em Galinhos versus qualidade ambiental do núcleo populacional; expansão da ocupação em terrenos de marinha e de uso de bem comum do povo na orla de Galos e Galinhos versus erosão costeira; poços para abastecimento versus expansão de construções em Galos; perda de terreno (recuo da linha de costa) versus inundação de ruas e residências pela erosão costeira; expansão

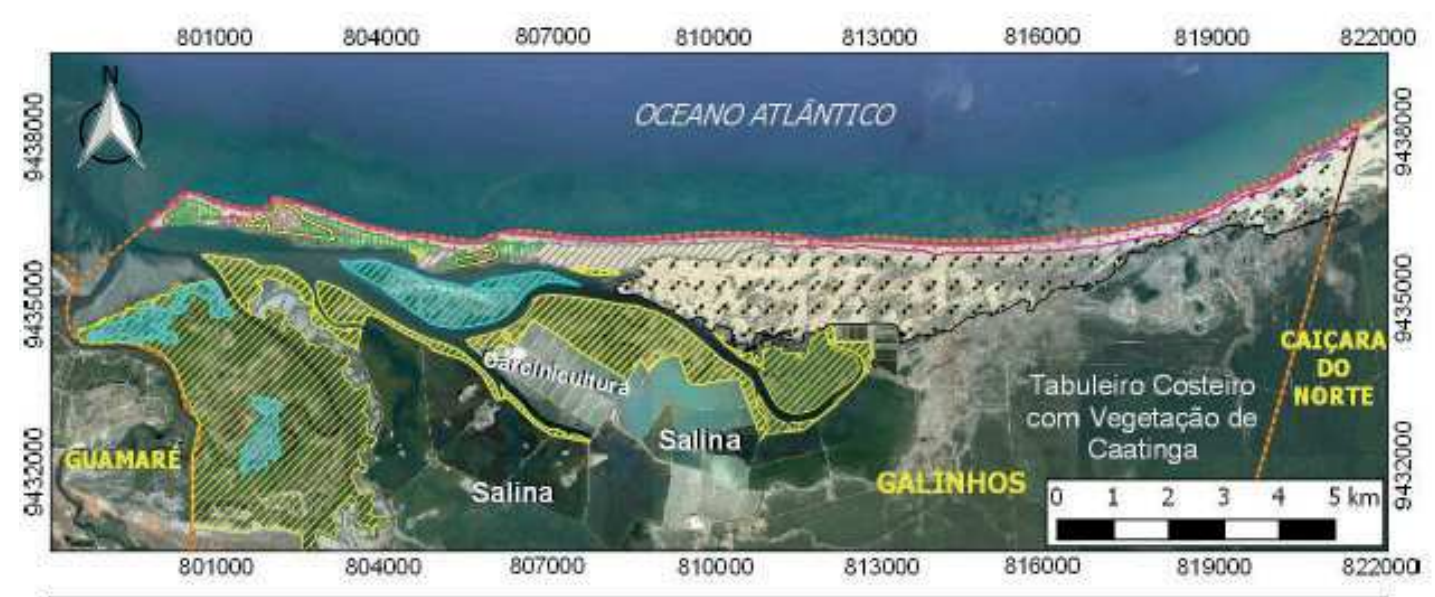

\begin{tabular}{|c|c|c|}
\hline \multicolumn{3}{|l|}{ Legenda } \\
\hline $\begin{array}{l}\text { - Areas Inscritas SPU } \\
\square \text { Limites Municipais } \\
\text { Mancha Urbana }\end{array}$ & $\begin{array}{l}\text { Ilhas Estuarinas } \\
\text { Manguezal } \\
\text { Dunas Móveis }\end{array}$ & $\begin{array}{l}\text { Dunas Semifixas } \\
\text { Área Mista: dunas frontais, praias, arenitos } \\
\text { Area Mista: dunas móveis e semifixas }\end{array}$ \\
\hline $\begin{array}{l}\text { Tै GOVERNO DO ESTAD } \\
\text { RIO GRANDE DO NOF }\end{array}$ & D馬 & $\begin{array}{l}\text { Fonte: Imagem Google Earth de } 06 \text { de maio de } 2016 \\
\text { Projeção UTM - Datum WGS-1984 Zona } 24 \text { Sul }\end{array}$ \\
\hline
\end{tabular}

FIGURA 7 - Unidades de Paisagem da orla do Município de Galinhos/RN. 
da ocupação em área de manguezal por empreendimentos de carcinicultura.

Outra constatação foi referente ao desconhecimento da população sobre a importância dos recifes existentes nas praias para contenção da erosão marinha. Tal fato os leva a retirar parte dessas rochas para utilizá-las nas construções, tendo em vista a dificuldade de adquirir material a partir de cidades distantes, somada à limitação do transporte, feito apenas por barco ou por automóveis off-road.
Dentre o conjunto de conflitos listados, 19\% estavam relacionados diretamente com a erosão costeira. Isto demonstra que a população tem conhecimento dos problemas existentes atrelados a este fenômeno, mesmo sem ter um conhecimento mais aprofundado sobre a problemática e dos riscos que a península corre com a perda de sedimentos em área tão diminuta (Figura 8). O segundo dia de trabalho foi dedicado à visita aos locais demarcados pela população como áreas de conflitos. As equipes
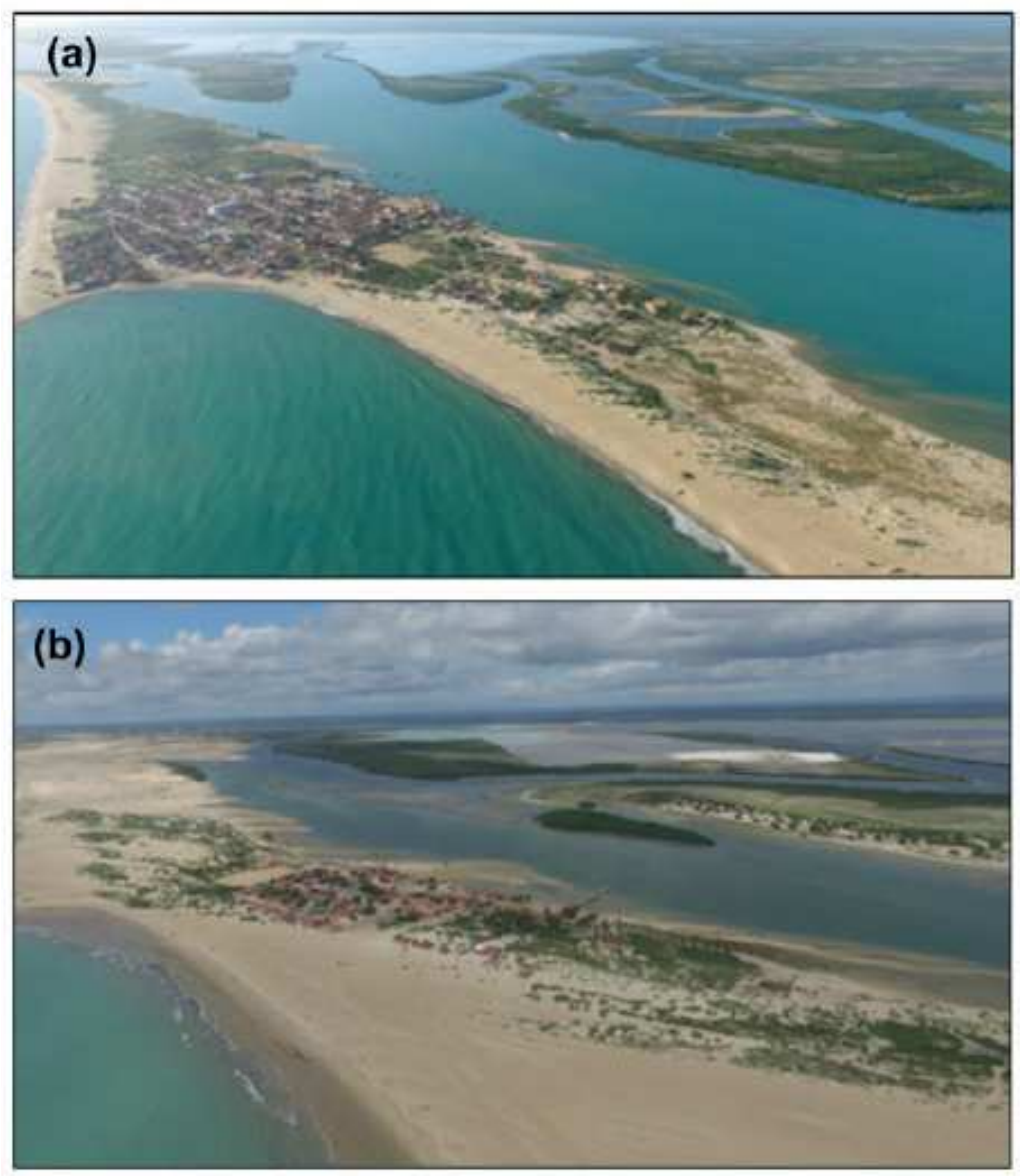

FIGURA 8 - Península de Galinhos e as Unidades de Paisagem. (a) Península e estuário; sede municipal. (b) Distrito de Galos. Foto por Daniel Maciel, 2017. 
discutiram in loco as informações identificadas a partir da leitura na imagem de satélite e validaram a delimitação dos trechos para ações específicas do PGI, de acordo com as questões levantadas pelos atores envolvidos.

Importante ressaltar que o município de Galinhos, pela sua fragilidade ambiental, já foi submetido a grandes impactos, sendo o mais importante e antigo (década de 1980) a destruição de significativa área de manguezal pela implantação de salina e em seguida por viveiros de produção de camarão em cativeiro (Figura 7).
Um dos motivos para o arrefecimento da implantação do PGI, além da mudança da administração local, foi o conflito entre a implantação de parque eólico em campo de dunas móveis, as Dunas do Capim, e o passeio turístico em veículos off-road 4X4 e buggy, para acesso ao braço de mar adjacente ao manguezal. A frustração gerada pela implantação do parque eólico nas dunas móveis, contrariando a mobilização popular que reivindicava a redução do número de aerogeradores, também contribuiu para a desaceleração do Projeto Orla. A população local expressou durante a oficina que se sentiu prejudi-

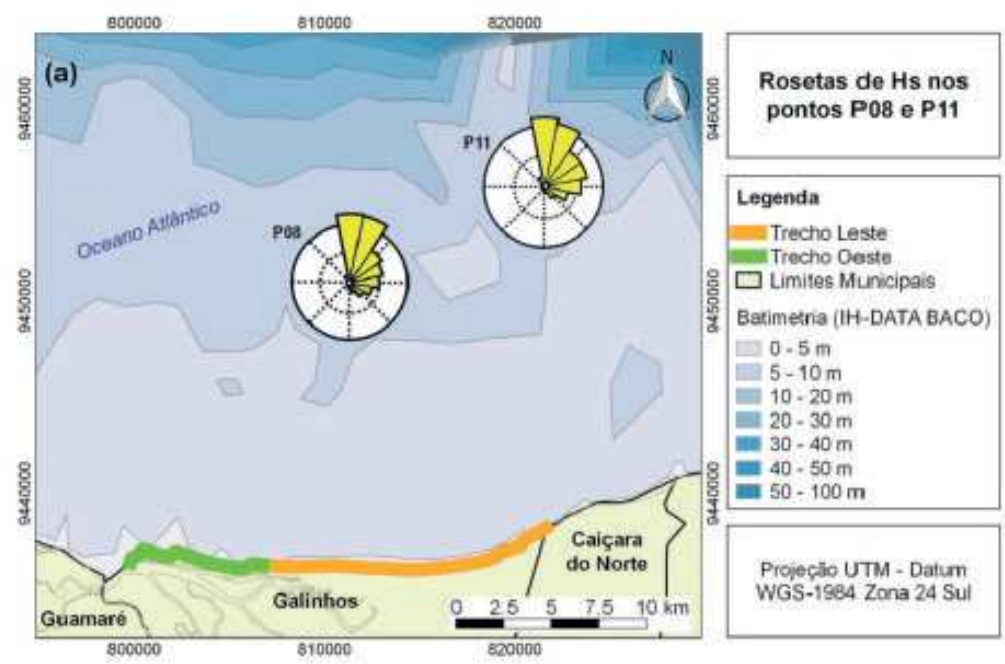

(b) P08

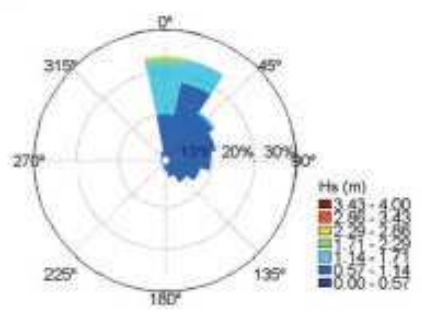

(c) P11

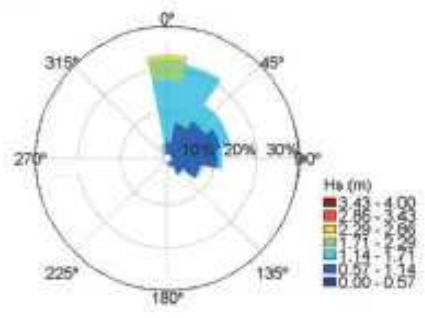

FIGURA 9 - Rosetas de Hs dos pontos P08 e P11, oriundo da análise no SMC-Brasil. 
cada quanto aos passeios turísticos pelas dunas, à utilização das lagoas interdunares e ao acesso ao braço de mar para banho e lazer.

Com a mudança da administração municipal, abriu-se a possibilidade da retomada do PGI a partir da demonstração de interesse do novo Prefeito em estabelecer a gestão participativa da orla. Assim sendo, a população renovou a vontade de exercer o seu papel de sujeito ativo na definição das políticas relacionadas ao meio ambiente, ao turismo, à pesca e ao uso e à ocupação do solo do município. Esse histórico de conflito entre os interesses da população e a pressão econômica para utilização dos recursos ambientais do local leva a sociedade organizada a valorizar o planejamento participativo, por entender que, assim, os seus interesses poderão ser considerados pelos tomadores de decisão.
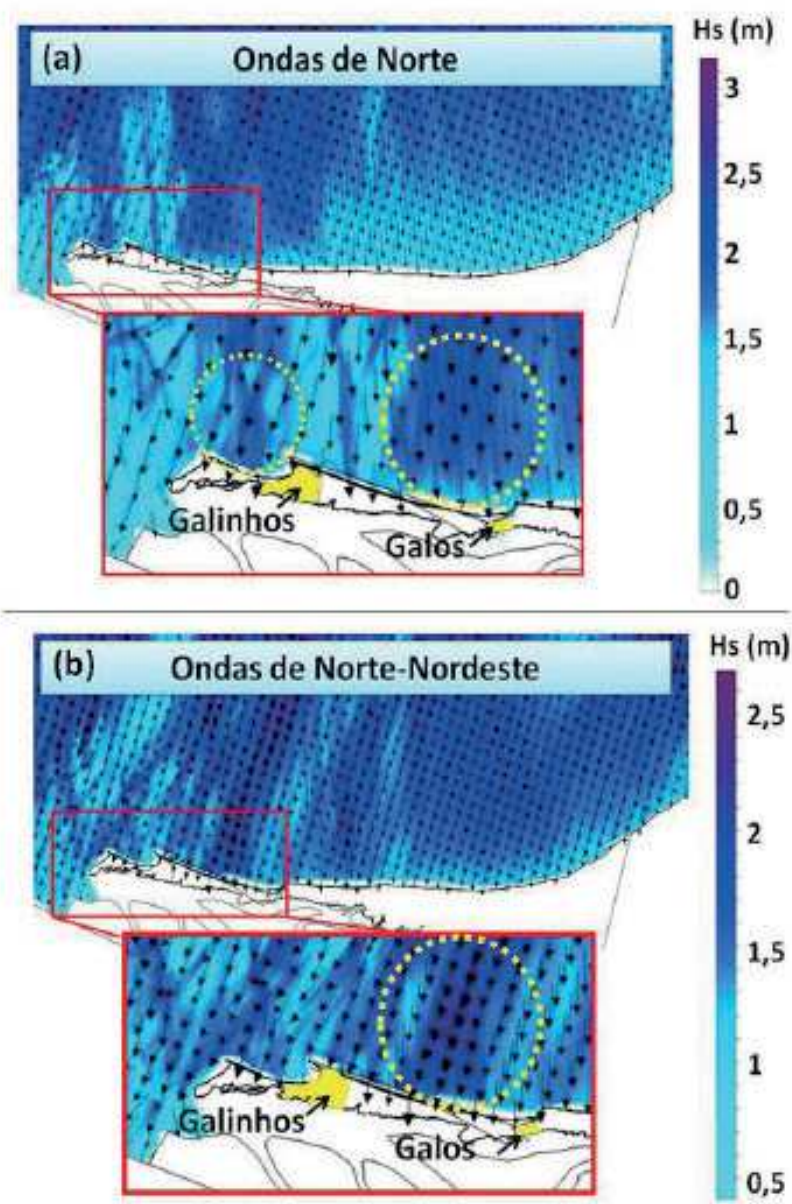

FIGURA 10 - Representação da magnitude de Hs resultante da propagação de ondas vindas de (a) norte e de (b) norte-nordeste, ambas em preamar de tempestade, simulada no SMC-Brasil. Círculos destacam locais de intensificação de energia da onda incidente. 
Considerando-se o aspecto da erosão costeira na área de estudo, o clima de ondas - que define a energia da ação marítima sobre a orla - para o trecho oeste foi definido pelo ponto P08 (em profundidade de $10,45 \mathrm{~m}$ ) e pelo ponto P11 para o trecho leste (cota batimétrica de 10,49 m). As ondas chegam à plataforma continental rasa principalmente de norte, norte-nordeste, nordeste e leste-nordeste (Figura 9), variando principalmente de acordo com o deslocamento sazonal da ZCIT. Têm valores de Hs entre 1,73 e 1,12 m em condições médias, aumentando para entre 3,28 e 1,36 m durante tempestades.

A linha de costa na enseada da sede recebe ondas entre 1,40 e 1,90 m durante eventos de tem- pestade. A linha de costa adjacente a Galos recebe ondas entre 1,50 e 1,70 m nestas mesmas condições. Ondas entre 0,70 e 1,40 m em média incidem sobre o restante da orla. Como a densidade de energia média por unidade de área da onda incidente é diretamente proporcional ao valor de Hs, a energia mais intensa de ondas incide sobre a península bem próxima à sede de Galinhos, bem como em frente ao distrito de Galos, principalmente nas situações de ondas vindas de norte e norte-nordeste, em preamar em tempestade (Figura 10). Concentrações de maiores valores de Hs são representadas na imagem da Figura 10 com cores em azul mais escuro e destacadas com círculos, a oeste da sede municipal e do Distrito de Galos.

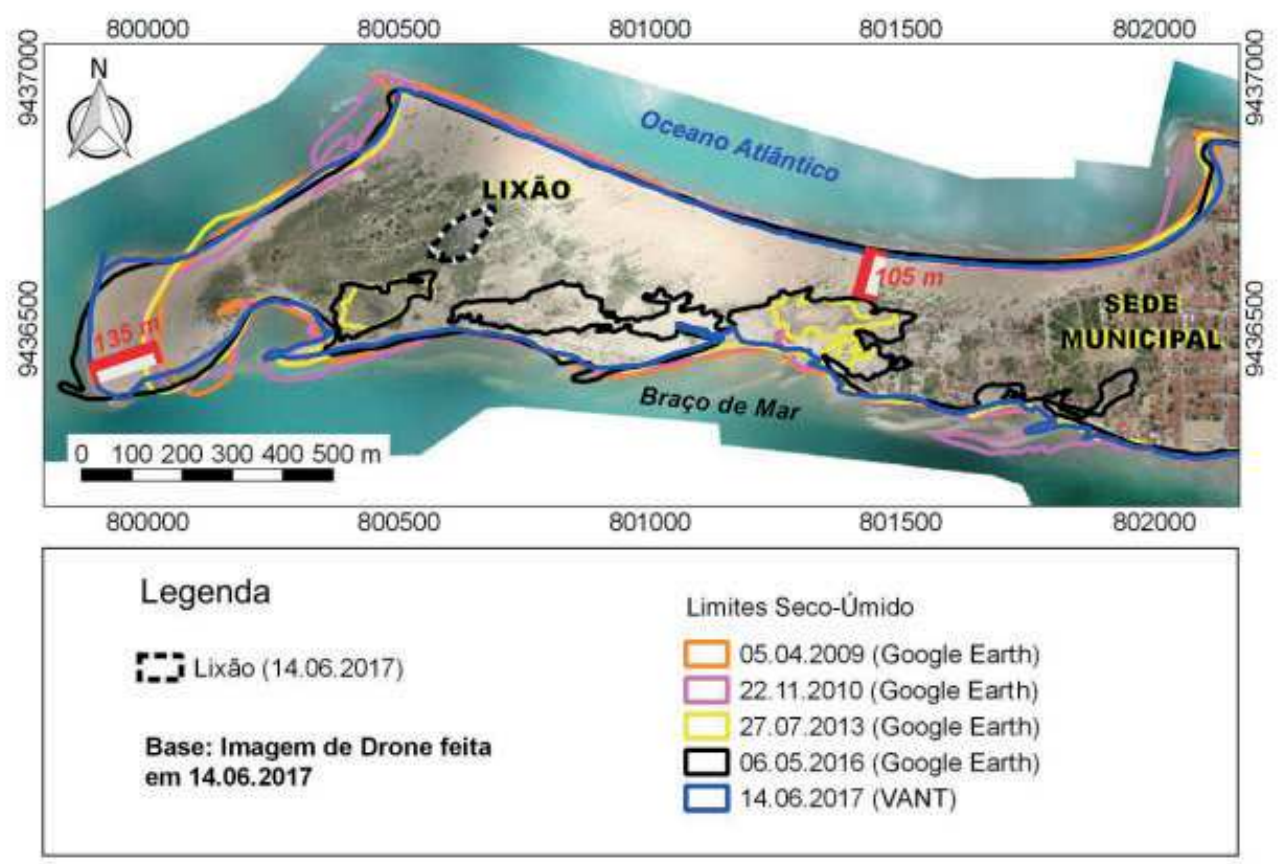

FIGURA 11 - Análise multitemporal por imagens de Sensoriamento Remoto do limite seco-úmido na península de Galinhos. 


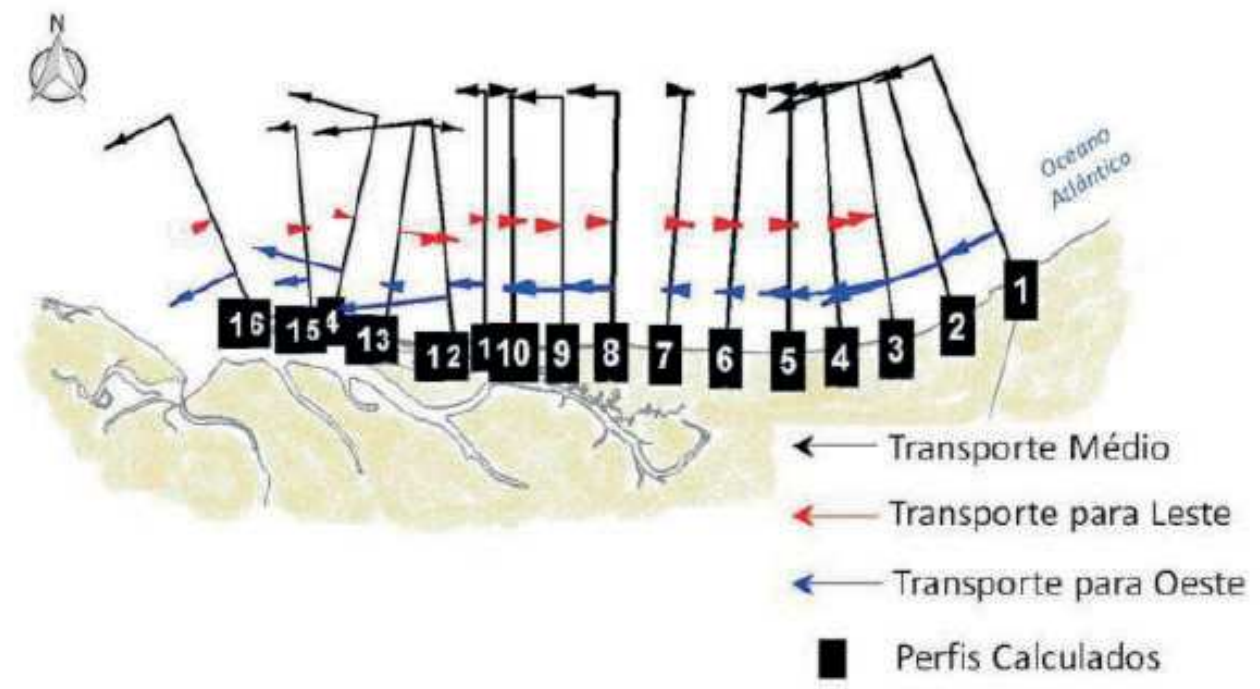

FIGURA 12 - Transporte longitudinal médio de sedimentos calculado no SMC-Brasil.

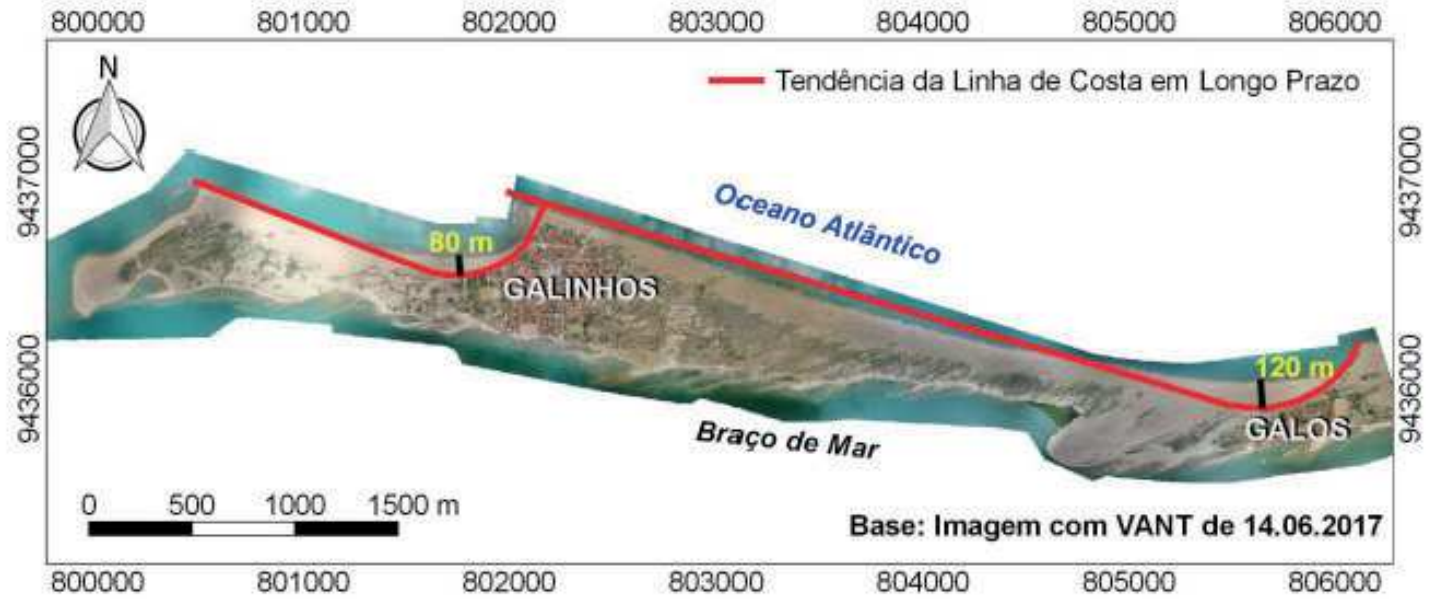

FIGURA 13 - Linha de tendência da planta de equilíbrio das praias em enseada em frente à sede municipal de Galinhos e ao Distrito de Galos. 
Nesses locais de incidência de ondas com maior Hs, foi identificada uma tendência de abertura de uma barra de maré. O alcance mínimo da água no terreno foi traçado pelo limite seco-úmido na composição visível das imagens oriundas do Google Earth $^{\odot}$ e do imageamento realizado com VANT (Figura 11). As imagens indicam o alcance da água nesse ponto desde o ano de 2013, pelo lado do estuário. A concentração de energia de ondas marítimas identificada na modelagem reforça a possibilidade de que o local onde se situa o farol da barra poderá ser insulado. Para uma análise mais profunda da dinâmica de separação e continentalização de pontas, barras e ilhas barreiras no RN, é necessário considerar lineamentos tectônicos relacionados ao Sistema de Falhas Afonso Bezerra-Carnaubais, mapeados por Silva et al. (2010) e Rios \& Amaro (2012) naquela região. Esta dicussão é pretendida em etapas futuras, como continuidade a esta pesquisa.

O núcleo habitacional de Galinhos está expandindo-se na direção da ponta do farol e do local onde é depositado lixo a céu aberto (Figura 11). No ano de 2016, a faixa de areia emersa entre a orla marítima e a orla interna chegou ao mínimo de 105 m de extensão. As dunas frontais existentes no trecho são pouco vegetadas e podem ser facilmente demovidas pela ação da água, que chega tanto do mar quanto do canal estuarino.

O carreamento de sedimentos pelas correntes na orla interna da península pode estar alimentando o crescimento observado do pontal, que avançou aproximadamente $135 \mathrm{~m}$ para oeste entre os anos de 2009 e 2017 . Situa-se em local mais protegido das correntes e da energia das ondulações marítimas e, portanto, mais propício à deposição (Figura 10).
O fluxo médio anual de energia de ondas entre 1948 e 2008 foi calculado em 366,43 J/m.s na região de Galinhos, com transporte longitudinal de sedimentos resultante de leste para oeste, acompanhando a deriva litorânea relacionada à Corrente Norte do Brasil (Figura 12). As taxas de transporte têm média anual de $185.839 \mathrm{~m}^{3} /$ ano no trecho da península e $163.361 \mathrm{~m}^{3}$ /ano no trecho leste. Em termos de sazonalidade, os meses de setembro, outubro e novembro são os de maior transporte, responsáveis por $58.189 \mathrm{~m}^{3} /$ ano no trecho oeste e média de $49.797 \mathrm{~m}^{3} /$ ano no trecho leste da orla marítima de Galinhos. A região da península apresenta maior taxa de transporte de sedimentos em relação ao trecho leste para todos os meses do ano.

O cálculo da planta de equilíbrio apresentou tendência de avanço da linha de costa em longo prazo de aproximadamente $80 \mathrm{~m}$ em direção à sede municipal de Galinhos e de 120 m em direção ao Distrito de Galos (Figura 13), sobrepondo-se à imagem do VANT. Já ocorrem avanços do mar durante as marés mais altas do ano e há relatos do nível da água atingindo o arruamento da sede do município. Entretanto, não se dispõe de registro fotográfico nem por sensoriamento remoto de tais eventos de inundação.

\section{Considerações finais}

A rápida mudança física que ocorre em Galinhos, especialmente na faixa de terra com influência direta do mar, aponta para a necessidade de que se estabeleça o planejamento territorial, com o apoio de tecnologias que assegurem a inserção de conhecimentos fundamentais à gestão ambiental costeira. 
Considera-se também a importância da transferência desse conhecimento técnico-científico para a população local, bem como a absorção do conhecimento local pela equipe técnica responsável pela condução dos trabalhos. Vale ressaltar a importância da interação entre gestores e população na discussão e na aplicação de saberes e de experiências das pessoas que vivenciam cotidianamente aqueles espaços.

Os instrumentos de planejamento e gestão em processo de elaboração deverão considerar cenários futuros e adaptações às mudanças climáticas, para orientar com segurança as possibilidades de expansão ou de realocação das áreas necessárias a novas construções dos núcleos populacionais.

Inicialmente, a população descortinou a possibilidade de expansão com novas construções nos lugares onde residem historicamente. Entretanto, constatou-se que dentre os conflitos identificados estão as construções versus a erosão costeira pelo avanço da linha de costa, pelo assoreamento do canal estuarino, ou ainda pela migração das dunas sobre as casas.

Diante destas averiguações, considera-se que o SMC-Brasil tem capacidade de prognosticar maiores pressões da erosão costeira, expandindo dados pontuais a todas as praias de Galinhos e implementando séries temporais longas, mesmo em cenário de escassez de dados primários das dinâmicas marinha e sedimentar.

Importante dar continuidade a este estudo com a modelagem na orla abrigada, para se compreender o papel da mobilização dos sedimentos das dunas no sentido do canal e a sua relação com a manutenção da península. O presente estudo, corroborado pela observação dos moradores, constatou que há a possibilidade do rompimento da península em local situado entre a sede municipal de Galinhos e a ponta do farol.

No planejamento e gestão da zona costeira, especialmente das faixas de praia submetidas a processos de perda ou ganho de sedimentos, não há mais como prescindir da utilização de modelos que possam orientar as formas mais adequadas de uso e ocupação desta faixa territorial, apesar das dificuldades de estrutura técnica e desconhecimento dessas tecnologias por parte do setor público.

Os Planos de Gestão Integrada da Orla Marítima e o SMC-BRASIL são metodologias que se complementam, permitindo que a população em geral e os tomadores de decisão adquiram maior conhecimento sobre a dinâmica costeira como indicador fundamental para planejar o uso sustentável da orla marítima. Essas metodologias permitem a participação efetiva da população nas discussões e na socialização de conhecimentos e saberes sobre a orla, possibilitando a sua inserção nos instrumentos de planejamento e gestão, pela participação efetiva dos habitantes nas decisões relacionadas ao planejamento territorial.

É fundamental que o novo PGI considere a erosão no ordenamento da orla marítima aqui identificada e modelada, no sentido de mitigar os efeitos da perda de terreno, evitando a expansão dos usos nos espaços adjacentes à praia. As oficinas para a conclusão da revisão do PGI incluirão as discussões sobre o PDP, no que concerne às áreas que extrapolam a orla marítima. A integração desses dois instrumentos permitirá que a lei municipal que instituirá o Plano Diretor Participativo assegure a implantação das ações sobre o disciplinamento do uso da orla marítima.

O SMC-Brasil possibilita a socialização de conhecimentos sobre áreas específicas entre os 
diversos atores envolvidos na gestão dos espaços costeiros, pelo uso das bases de dados que compõem o próprio sistema, associado às observações in loco das populações tradicionais.

\section{Agradecimentos}

As autoras agradecem ao Ministério do Meio Ambiente (MMA), ao Instituto de Desenvolvimento Sustentável e Meio Ambiente do RN (IDEMA) e à Universidade Federal do Rio Grande do Norte (UFRN), que permitiu trazer o SMC-Brasil para o $\mathrm{RN}$ e promover a capacitação de corpo técnico para o uso da ferramenta. Ao IDEMA, pelos recursos que viabilizaram a presença e o envolvimento das autoras nas oficinas participativas e a execução da modelagem costeira. À Prefeitura Municipal de Galinhos, pelo espaço aberto para discussão e apoio às oficinas participativas no âmbito do Projeto Orla.

\section{Referências}

Almeida, L. R.; Amaro, V. E.; Marcelino, A. M. T.; Scudelari, A. C. Avaliação do clima de ondas da praia de Ponta Negra (RN, Brasil) através do uso do SMC-Brasil e sua contribuição à gestão costeira. Revista da Gestão Costeira Integrada, 15(2), 135-151, 2015. doi: 10.5894/rgci532

Álvares, C. A.; Stape, J. L.; Sentelhas, P. C.; Gonçalves, J. L. M.; Sparovek, G. Köppen's climate classification map for Brazil. Meteorologische Zeitschrift, 22(6), 711-728, 2014. doi: 10.1127/0941-2948/2013/0507

Araújo, D. J. C.; Scudelari, A. C.; Amaro, V. A. Evolução decadal da taxa de transporte longitudinal de sedimento em praias urbanas da zona costeira de Natal/RN. In: Anais do VIII Congresso sobre Planejamento e Gestão das Zonas Costeiras dos Países de Expressão Portuguesa. Aveiro, 14-16 de out., 2015. Disponível em: <http://www.aprh.pt/
ZonasCosteiras2015/pdf/P02_Poster_104.pdf >. Acesso em: ago. 2017.

Camus, P.; Méndez, F. J.; Medina, R.; Tomas, A.; Izaguirre, C. High resolution downscaled ocean waves (DOW) reanalysis in coastal areas. Coastal Engineering, 72, 56-68, 2013. doi: 10.1016/j.coastaleng.2012.09.002

Davis, J. L. A morphogenetic approach to world shorelines. Zeitschrift fur Geomorphologie, 8, 127-142, 1964. Disponível em: http://liblists.sussex.ac.uk/items/CC49DDD0-1FA8-743B-FEAD-DF60AD373B5B.html

González, M.; Medina, R. On the application of static equilibrium bay formulations to natural and man-made beaches. Coastal Engineering, 43, 209-225, 2001. doi: 10.1016/ S0378-3839(01)00014-X

Gorelick, N.; Hancher, M.; Dixon, M.; Ilyushchenko, S.; Thau, D.; Moore, R. Google Earth Engine: Planetary-scale geospatial analysis for everyone. Remote Sensing of Environment, 2017. doi: 10.1016/j.rse.2017.06.031

Hsu, J. R. C.; Evans, C. Parabolic bay shapes and applications. Proceedings of the Institution of Civil Engineers, 87(4), 557-570, 1989. doi: 10.1680/iicep.1989.3778

IH-Cantábria. Documento Temático de Ondas. Santander: Universidade de Cantábria, 2012. Disponível em: $<$ http:// smcbrasil.ihcantabria.com/descargas/ $>$. Acesso em: ago. 2017.

IH-Cantábria. Sistema de Modelado Costeiro - Manual de Referência. Santander: Universidade de Cantábria, 2013. Disponível em: <http://smcbrasil.ihcantabria.com/descargas/>. Acesso em: ago. 2017.

IBGE - Instituto Brasileiro de Geografia e Estatística. Cidades@Galinhos: Número Populacional de acordo com censo de 2010. Disponível em: <https://cidades.ibge.gov.br/ v4/ brasil/rn/galinhos/ panorama > . Acesso em: maio 2017.

Lima, Z. M. C.; Vital, H.; Tabosa, W. F.; Santos, D. A. S. Estudo da variação morfológica de perfis praiais no spit de Galinhos-RN, Nordeste do Brasil. In: Anais da IX Congresso da Associação Brasileira de Estudos Quaternários. Recife, 2003. Disponível em: <http://www.abequa.org.br/trabalhos/ quatcost_184.pdf>. Acesso em: ago. 2017.

Loureiro-Filho, L. S. A competência do município na zona 
costeira urbana. São Paulo, Tese (Doutorado em Direito) - USP, 2014.

Matos, M. F. A.; Fortes, C. J.; Amaro, V. E.; Scudelari, A. C. Análise comparativa da agitação obtida com o Modelo Numérico (SWAN) na modelagem de ondas do Litoral Setentrional do Rio Grande do Norte, Brasil e Dados de Campo. Revista de Gestão Costeira Integrada, 3, 289-299, 2013. doi: 10.5894/rgci378

Melo, A. B. C.; Cavalcanti, I. F. A.; Souza, P. P. Zona de Convergência Intertropical do Atlântico. In: Cavalcanti, I. F. A.; Ferreira, N. J.; Silva, M. G. A. J.; Dias, M. A. F. S. (Orgs.). Tempo e clima no Brasil. São Paulo: Oficina de Textos, 2009. p. 25-41.

MMA - Ministério do Meio Ambiente; SPU - Secretaria do Patrimônio da União. Projeto Orla: Manual de Gestão. Brasília: MMA/SPU, 2002a.

MMA - Ministério do Meio Ambiente; Ministério do Planejamento, Orçamento e Gestão. Projeto orla: fundamentos para gestão integrada. Brasília: MMA, 2002b.

MMA - Ministério do Meio Ambiente. Áreas Prioritárias para a Conservação de Biomas Brasileiros, 2003. Disponível em: <http://www.mma.gov.br/biodiversidade/ projetos-sobre-a-biodiveridade/projeto-de-conserva\%C3\%A 7\%C3\%A3o-e-utiliza $\%$ C3\%A 7\%C3\%A3o-sustent $\% \mathrm{C} 3 \% \mathrm{~A} 1$ vel-da-diversidade-biol $\% \mathrm{C} 3 \% \mathrm{~B} 3$ gica-brasileira-probio-i $/ \% \mathrm{C} 3 \% \mathrm{~A} 1$ reas-priorit $\% \mathrm{C} 3 \% \mathrm{~A} 1$ rias $>$. Acesso em: ago. 2017.

MMA - Ministério do Meio Ambiente; IH-CANTÁBRIA - Instituto de Hidráulica Ambiental da Universidade de Cantábria; UFSC - Universidade Federal de Santa Catarina. Projeto SMC-Brasil: Recomposição de Praias. Brasília: MMA, 2014. Disponível em: $<$ http://smcbrasil.ihcantabria. com/descargas/>. Acesso em: ago. 2017.

Oliveira, M. (Org.). Diálogos Brasil-Espanha: Sistema de Modelagem Costeira. Brasília: IABS, 2013. ISBN: 97885-64478-15-2
Pessoa-Neto, O. C.; Soares, U. M.; Silva, J. G. F.; Roesner, E. H.; Florêncio, C. P.; Souza, C. A. V. Boletim de Geociências Petrobras: Bacia Potiguar. Rio de Janeiro: Petrobras, 2007. Disponível em: <http://vdpf.petrobras.com.br/vdpf/ consultarArquivosEdicao.do?acao=preparaTela\&CODIGO_EDICAO_CONSULTA_ARQUIVO $=41>$. Acesso em: ago. 2017.

Peterson, R. G.; Stramma, L. Upper-level circulation in the South Atlantic Ocean. Progress in Oceanography, 26(1), 1-73, 1991. doi: 10.1016/0079-6611(91)90006-8

Ribeiro, R. S.; Bonetti, J.; Klein, A. H. F. Caracterização morfológica e hidrodinâmica de praias do Estado de Santa Catarina com vistas à avaliação de perigo ao banhista. Geosul, 30(60), 49-68, 2015. doi: 10.5007/2177-5230.2015v30n60p49

Rios, V. P. L.; Amaro, V. E. Caracterização dos depósitos sedimentares Holocênicos no sistema de ilhas barreiras do estuário Diogo Lopes, litoral setentrional do Rio Grande do Norte. Revista de Geologia, Hidrosema-UFRN, 25, 55-69, 2012.

Silva, D. R. V.; Amaro, V. E.; Souto, M. V. S.; Nascimento, M. C.; Pereira, B. R. B. Geomorfologia de uma área com alta sensibilidade ambiental na Bacia Potiguar (NE do Brasil). Revista da Gestão Costeira Integrada, 10(4), 545-566, 2010. Disponível em: http://www.aprh.pt/rgci/ pdf/rgci-218_Silva.pdf

Silva, I. R.; Guimarães, J. K.; Bittencourt, A. C. S.; Rodrigues, T. K.; Andrade-Neto, G. F. Modelagens de clima de ondas e transporte sedimentar utilizando o SMC-Brasil: aplicações para a praia do Forte, litoral norte do Estado da Bahia. Revista Brasileira de Geomorfologia, 17(4), 743761, 2016. doi: 10.20502/rbg.v17i4.814

Vital, H.; Stattegger, K.; Amaro, V. E.; Schwarzer, K.; Frazão, E. P.; Tabosa, W.; Silveira, I. M. A modern high-energy siliciclastic-carbonate platform: continental shelf adjacent to Northern Rio Grande do Norte State, Northeastern Brazil. SEMP Special Publication: Recent Advances in Models of Siliciclastic Shallow-Marine Stratigraphy, 90, 175-188, 2008. doi: 10.2110/pec.08.90.0177 